\title{
Concomitant Medication Use End Day
}

National Cancer Institute

\section{Source}

National Cancer Institute. Concomitant Medication Use End Day. NCI Thesaurus. Code C83226.

The day of the week that concomitant medication usage ended. 